\title{
TITLE:
}

\section{Letter from Kigoma, 29 August 1995}

$\operatorname{AUTHOR}(\mathrm{S})$ :

\section{CITATION:}

Letter from Kigoma, 29 August 1995. Pan Africa News 1995, 2(2): 6-6

ISSUE DATE:

1995-10

URL:

http://hdl.handle.net/2433/143328

\section{RIGHT:}

Copyright (C) Pan Africa News. 


\section{STATUS UPDATE ON THE "OK" (ORPHANED KIGOMA) CHIMPS}

Ed. note: A previous issue of PAN (Pan Africa News Vol. 2, No. 1, Winter 1995) reported that six young chimpanzees had been confiscated in Kigoma/Ujiji township (western Tanzania) in 1994. The following update on the status of the chimps was submitted by $\mathrm{Mr}$. Edeus T. Massawe, the Acting Director of the Mahale Wildilife Research Centre and Interim Secretary of the Committee for the Survival of the Kigoma Orphaned Chimpanzees).

Of the six young chimps confiscated in Kigoma /Ujiji township in March 1994, one female, SUBIRI, died while being treated for her illnesses. The remaining five chimps, named RAFIKI, DOSI, ZORRO, KIPARA and KARANGA (KARANGA is now the only female in the group) are doing well under the care of the Jane Goodall Institute (JGI) and are still temporarily sheltered on the Aqua Products Ltd. premises in Kigoma.

At the time of the chimps' confiscation, investigations into illegal trafficking in live, wild chimpanzees in western Tanzania had been going on for five years. These investigations were initiated due to unconfirmed reports of an illegal trade in infant chimpanzees which possibly involved the death of large numbers of their adult companions. The aim of the trade was to supply an increasing international demand for wild-caught chimpanzees for use in laboratories, zoos and the entertainment and pet trade. It was within the scope of these investigations that the six young chimps were confiscated in Kigoma. Two suspects were arrested and handed to the local police in connection with the case 
which also involved the smuggling of 66 African grey parrots, and court proceedings were initiated by the authorities. To the surprise of those who arrested them, charges against these culprits were dropped by the higher court and the accused were set free. The chimpanzees which were alleged to come from a neighboring country were forfeited to the government and remained under the care of JGI personnel. Almost all of the birds died; the few survivors were put under private care. A permit allowing the Director of Gombe Stream Research Centre to erect suitable facilities at Kitwe peninsula on the outskirts of Kigoma Township on the Lake Tanganyika shore to serve as a permanent sanctuary for the five chimpanzees was issued on 14 March 1995.

The decision to keep the chimpanzees in a sanctuary in Kigoma was reached after much consideration. Among the concerns was the obvious difficulty and threat to the chimps' welfare if any attempt was made to return them to the wild. The chimps, still very young, needed some substitute for their mothers' care. An additional concern was that there was no sure proof of their place of origin, and furthermore the intensely territorial nature of chimpanzee groups and evidence that they will show extreme hostility to newcomers made it highly probable that the young chimps would not survive a reintroduction. It was doubtful that the youngsters had yet acquired the survival and social skills necessary for life in the wild.

The surviving chimps are now awaiting the development of their new home on Kitwe peninsula. Appropriate shelters and fencing are to be installed at the site which was once used by the Wildlife Department as a Zoo and Conservation Education Centre for Kigoma. JGI is prepared to find funding to develop the area as a Chimpanzee Sanctuary and Conservation Education Centre where visitors could be shown videos of local wildlife including the rich acquatic fauna of Lake Tanganyika and also a museum to house JGI's "Understanding Chimpanzees" exhibits. The chimpanzees will get a home as close as possible to a natural environment where they will be protected and looked after by people who care. They still, however, will need outside support.

We take this opportunity to thank all those who contributed precious time, resources and moral support to help the unfortunate victims of the greedy dealers in the illicit animal trade. We are saddened still by the trágic death of SUBIRI who did not survive the traumatic episode of being taken from her mother and her beautiful forest home to be sent into miserable captivity. We thank the Director, Gombe Stream Research Centre for accepting the Committee's request to take over the demanding responsibility of care for these orphans. On behalf of the Chairman of the Committee, Mr. Jayant Vaitha of Aqua Products Ltd., Kigoma, I thank the members of the Committee who helped during the difficult stage of rescuing the young chimps from their terrible situation. 